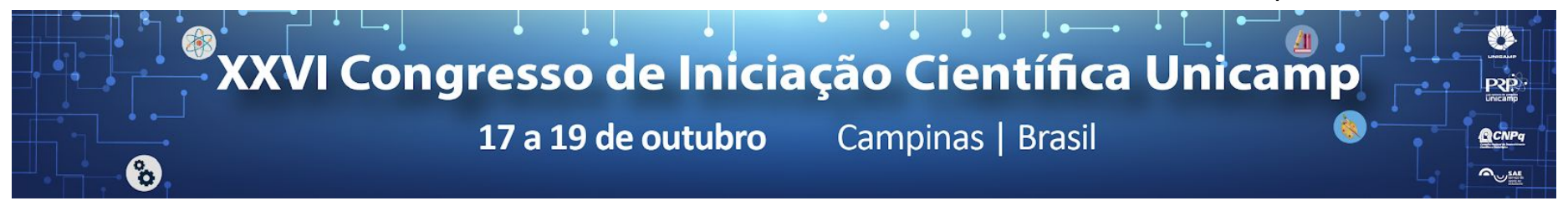

\title{
OESTE DA BAHIA: UMA DESCRIÇÃO QUANTITATIVA DOS INDICADORES DA EDUCAÇÃO.
}

\author{
Juan C. S. R. Lima*, Sandra Fernandes Leite
}

\section{Resumo}

Este projeto de Iniciação Científica é parte de uma pesquisa maior, o "MAPEAMENTO DAS METAS DO PLANO NACIONAL DE EDUCAÇÃO 2014-2024 NA REGIÃO DOS CERRADOS DO CENTRO-NORTE DO BRASIL: UM ESTUDO QUANTITATIVO E QUALITATIVO, de objetivo primeiro o mapeamento das metas do Plano Nacional de Educação (PNE) Lei $n^{\circ}$ 13005/2014 da Educação Básica na Região dos Cerrados dos Centro Norte do Brasil. Esse projeto de Iniciação Científica tem como objetivo fazer uma pesquisa quantitativa descritiva, isto é, levantamento e exposição de dados de uma determinada região, em específico a mesorregião do extremo oeste da Bahia no período relativo de 4 anos (2014-2018), visando achar indicadores que possam nos fornecer informações sobre a implementação e o desenvolvimento das metas do PNE. Intenciona-se, com a presente pesquisa, a reunião e o tratamento dos dados por meio do uso de métodos estatísticos facilitando a descrição quantitativa das características tanto da população, quanto da educação da região.

\section{Palavras-chave:}

Plano Nacional da Educação(PNE), Oeste da Bahia, Levantamento e Exposição de dados.

\section{Introdução}

O extremo oeste da Bahia faz parte de uma região, denominada informalmente de "MATOPIBA", nome dado em referência às iniciais dos estados que ela abrange. Região na qual vem havendo um crescente avanço tecnológico e um grande desenvolvimento nos processos de agricultura, tornando a região um forte ponto em produção, comercialização e exportação de alimentos.

Este projeto de pesquisa visa procurar, organizar e analisar estatisticamente os dados disponíveis nos diversos sites oficiais do governo no período relativo de 4 anos dessa região - formada pelos municípios de Barreiras, Luís Eduardo Magalhães, São Desidério, Riachão das Neves, Santa Rita de Cássia e Formosa do Rio Preto - buscando entender de quais maneiras a nova economia impacta nos indicadores das metas do Plano Nacional de Educação (PNE) Lei $n^{\circ} 13.005 / 2014$, com especial atenção às metas: 01-Educação Infantil; 02-Ensino Fundamental; 03-Ensino Médio; 08-Anos de Estudo; 09-Alfabetização; 10-Educação de Jovens e Adultos; 11-Educação Profissional Técnica de Nível Médio; 12-Ensino Superior; 15-Formação de Professores de Educação Básica no Ensino Superior.

\section{Resultados e Discussão}

Se tratando de um projeto de pesquisa quantitativa descritiva é imprescindível o uso de fontes para a obtenção dos dados, portanto o projeto iniciou-se com a catalogação das fontes oficiais de dados demográficos e sobre a educação ao longo do período destacado (IBGE, MEC/inep, Observatório do PNE, PNE em movimento, dentre outros).

O projeto ainda se encontra em suas etapas iniciais, entretanto já se nota uma extrema dificuldade na obtenção dos dados que deveriam ser públicos e de "fácil" acesso.

\section{Conclusões}

O passo inicial seria o estudo e análise das metas e seus indicadores para classificação de quais tipos de dados serão extraídos das fontes em relação à população (como a quantidade de pessoas, $\mathrm{PIB}, \mathrm{IDH}$, renda per capita, entre diversos outros) e a educação (número de escolas, matrículas, taxa de analfabetismo e outros), montando uma espécie de linha do tempo, tornando mais fácil a avaliação da variação dos dados ao decorrer do tempo.

Os dados obtidos, ou a falta deles, servirá futuramente para montar tabelas e, a partir de métodos estatísticos, inferir como a educação se comportou quantitativamente nesse período.

\section{Agradecimentos}

ALVES, V.E.L. (Org.). Modernização e regionalização nos cerrados do Centro-Norte do Brasil: Oeste da Bahia, Sul do Maranhão e do Piauí e Leste de Tocantins / Organizadores.

BRASIL. Lei 13.005, de 25 de junho de 2014. Aprova o Plano Nacional de Educação - PNE e dá outras providências. Disponível em: $<$ http://presrepublica.jusbrasil.com.br/legislacao/12509909 7/lei-13005-14>. Acesso em: 25 de nov. de 2016. 